\title{
ANALYSIS OF THE ITALIAN FOOTBALL IN THE 2016 EUROPEAN FOOTBALL CHAMPIONSHIP
}

\author{
Kemal Kurak ${ }^{1}$, \\ Hakan Büyükçelebi², \\ Mahmut Açak ${ }^{1 i}$ \\ ${ }^{1}$ Department of Coaching Education, \\ Çanakkale Onsekiz Mart University, \\ Turkey \\ ${ }^{2}$ Department of Coaching Education, \\ Inonu University, \\ Turkey
}

\begin{abstract}
:
The 15th European Football Championship (UEFA) was hosted by France. Italy exhibited a different football from this previous tournament. Italy participated in the European Football Championship 8 times, played three finals and won this trophy in 1968. Before 2016, Italian football is a team that has adopted the strict defense principle. It is aimed to reach the result based on standing balls and individual actions. With the 5-4-1 and 4-5-1 game system, the defense is not at risk and few players are attacked. In the preference of players, players with good defense power are preferred. In EURO 2016, Italy football; Looking at the comments from around the world, it has changed the style and style of the game. It is seen that it applies new trends in football. We can summarize some of these trends as follows; there is a very tactically trained team that can play different systems. Different game systems have been applied in different matches. It was observed that they wanted to direct the game by owning the ball. When they lost the ball, oppression was set up instead of waiting for the opponent to make mistakes. Distance between locations has been established as 35-40 m. Instead of waiting behind the ball, the opponent was directed to the press area to create pressure against the ball. These situations caused the Italian football team to play an attractive football.
\end{abstract}

Keywords: analysis, match analysis, Italy, national team, Italian Football

i Correspondence: email, hakan.buyukcelebi@inonu.edu.tr 


\section{Introduction}

In football, which is arguably the most popular sport in the world today, success requires high technical, tactical and physical skills (Helgerud et al., 2001; Manna et al., 2011). The European Football Championship is a football organization held every 4 years by UEFA since 1960. The tournament, which was founded as the European Cup of Nations, took its current name in 1968. The tournament is held among the top national football teams of the countries. Except for the host country, other teams are obliged to play pre-selection to participate in the tournament. 10 different national teams won the 15 tournaments played so far: Germany and Spain completed 3 times, France two times, the USSR, Italy, Czechoslovakia, Netherlands, Denmark, Greece and Portugal one time completed the tournament first. Spain won the tournament in 2008 and 2012. Thus, it bears the title of being the only team that can win the tournament in a row. Portugal won the final match of the tournament, which was held in France in 2016, in Paris, which beat France 1-0 in overtime. Éder recorded the only goal in the 109th minute.

Money spent in sports, sponsorship increased the interest in this sector and made it an ever-growing industry. In such a situation, it has been an inevitable result that technology branches benefit from the opportunities of technology (Mackenzie and Cushion, 2013). For this reason, training scientists try to develop new sports systems by making match analysis in computer environments while creating future athletes in sports laboratories using the tools and equipment of new technology (Sajad and Rahnama, 2007).

Over the past decade, analysis practices have become more popular among sports scientists in order to understand different performance indicators in team sports. Many analysts have used analyzes for many purposes, including technical-tactical evaluation, motion analysis, providing feedback, developing norms and modelling (Shafizadeh et al., 2013). Competition analysis means examining the events that occurred during the match and recording them objectively. This may be focused on a player's activities, as well as the actions and movements of the players around the ball (Hughes and Bartlett, 2002).

It is very important to determine and understand the relevant parameters in order to analyze the collective performance of teams in football and to ensure that the observation reaches the main goals (Carling et al., 2005). Analysis systems used for competition analysis in football can provide useful data about the statistics of the players' actions such as shooting, foul, passing, ball control and performance indicators of successful or unsuccessful teams. An indication of a performance parameter is the aggregation or selection of data to define the whole performance or several different aspects (Clemente et al., 2012).

While 24 teams struggle in the finals to win the 2016 Football European Championship held in France, we can say that the teams that can best demonstrate their team performance are in the semi-finals and finals. However, unlike previous tournaments, Italy played offensive football in this tournament. In this study, the way Italy plays the offensive football, which plays traditional defense football, was analyzed. 


\section{Method}

As the data collection tool, UEFA official website and international TV channel broadcasting research data competitions were determined. In competitions, technical systems such as the game systems of the teams and the lineup versions in the game, the variations of offensive in this lineup, the distribution of the goals scored and defeated by the time periods, the possession percentages according to the regions, total shot, shots on target, the corner kick, the offside, the number of successful and unsuccessful passes. parameters are examined in computer environment. The research data were analyzed by Instat analysis company for 51 different evaluation analysis programs for each team determined by the researchers, and some parameters were also analyzed using the paperpencil method. All the matches Italy played in the 2016 European Football Championship were recorded on video. In this study, computer controlled video analysis method was used. As an alternative to the paper and pencil analysis method, video analysis can provide more than one image, slowed motion, and replay of the movement, as well as making the viewable recording of the match. Video match analysis enables recording and analysis of all events. Technical and tactical performance was evaluated using video recordings and analysis methods (Lago-Peñas et al., 2010). Comprehensive analysis of video recording can be done to investigate the quantity of tactics and strategy in the soccer game (Luhtanen, 1990).

\section{Results}

Italy completed the group as the leader in the 2016 European Championship. In the qualifying round, the last champion was beaten by 2-0 in Spain and was defeated in Germany in the quarter-finals in penalty shootout.

\subsection{Italian Football Before Euro 2016}

Embracing the strict defense principle, Italy football was trying not to give space by keeping the bilateral struggles and the fields narrow in the 1st region. The center was kept crowded and it was expected that the opponent would make a mistake until the 1st zone. With the opponent's mistake, it was adopted to win the ball and attack with long balls or short vertical passes (counter attack). The aim was to reach the result based on individual actions and the desire to go to the result with standing balls. There was pressure on the opponent and referee by acting as a team psychologically. With the 5-41 and 4-5-1 game system, they were not at risk in defense and attacked with few players. In the loss of the ball, only passing behind the ball was expected patiently and concentrated until the opponent made a mistake and sliding was made according to the direction of the ball. In the preference of the players, the players with good defense power were preferred. 
Figure 1: 5-4-1 lineups of the Italian football team in the championships before Euro 2016

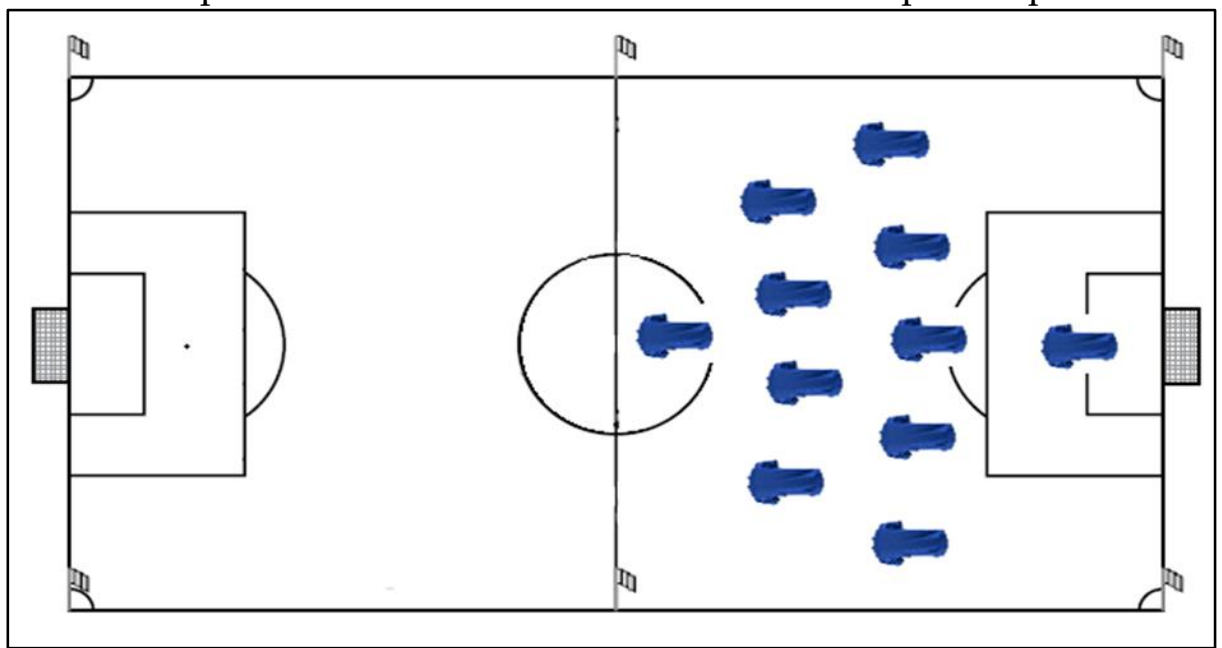

The 5-4-1 lineup is the most used game lineup. There are five defenders, four midfielders and one attacker. Sometimes 5-4-1 system was applied in the defense and especially midfield players were placed between the defense teams and no free space was left to the opposing team. The striker, on the other hand, directed the press that he applied to the wings and the catch area was created on the wings. The shape of this sequence is given above.

The 4-5-1 lineup is the second most used game lineup. There are four defenders, five midfielders and one attacker. The shape of this sequence is shown below.

Figure 2: 4-5-1 lineups of the Italian football team in the championships before Euro 2016

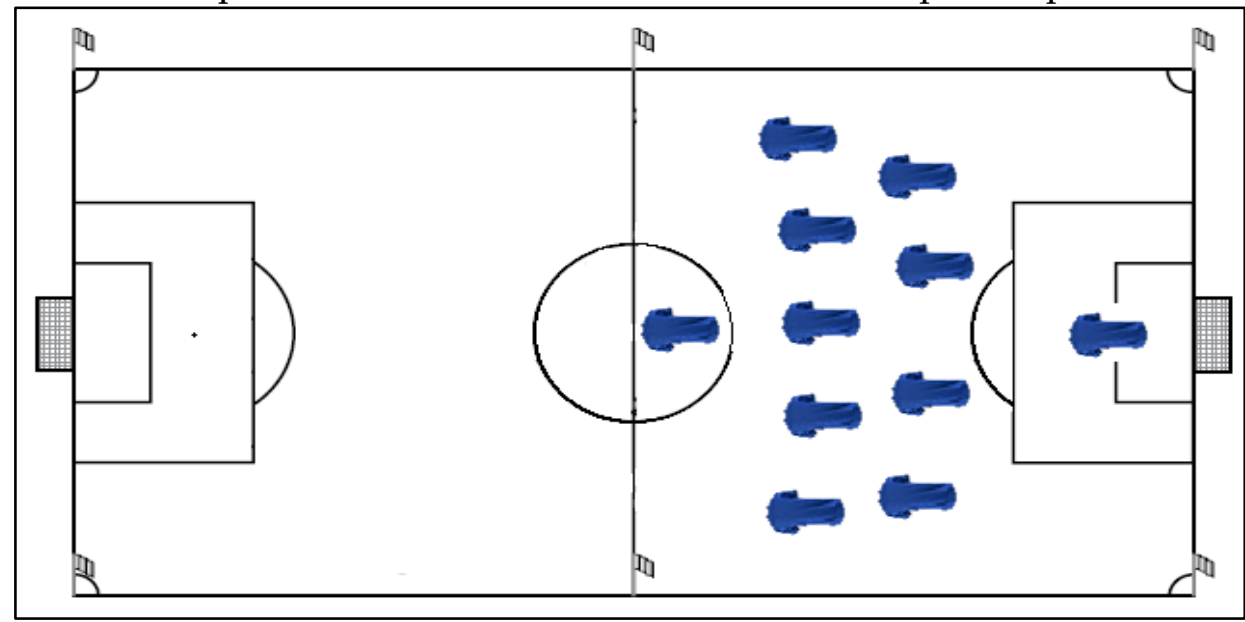

\subsection{Italian Football in Euro 2016}

It is the only team to score the least goals (1 goal) in the 2016 Football Championship and become the group leader. They saw two goals in their goal until they were eliminated in the quarter-finals. The duration of the attacks resulting in a goal is 12.4 seconds. They scored $75 \%$ of their goals from the resident attack. They did not see a goal from the free kick in their goal. While the fouls they committed in their own field fouled over the average of the tournament, they fouled below the average of the tournament in the 
opponent area. It is also the team that is at least offside in the tournament. The possession time of the ball is 5-15 seconds above the average of the tournament average. The average of the balls recovered in the opponent field and the speed of successful passes (15.8 meters) are also above the average of the tournament. As a result of the evaluation of the tournament on the basis of players, the following ranking was made as a result of the evaluations (Duration / Goal / Assist / Shooting - Finding the Goal / Fouls made / Pass / Lock Pass / Moves Defending / Moves Offense / Air Moves / Dribbling / Winning Balls / Winning Bouncing Balls on the Opponent Area) according to the positions of the Italian football players; Buffon, the goalkeeper of Italy, is the third most successful goalkeeper. Left back De Sciglio 11th out of 29 athletes, Right back Darmian 23th out of 30 athletes, Stoppers Chiellini 6th out of 72 athletes- Bonucci 10th, Front Libero 56th athlete De Rossi 16th-Thiago Motta 24 ' On the left, Giaccherini is 8th among 32 athletes-Eder 10th, righthanded Candreva is the 10th among 29 athletes, Attack midfielder Parolo is 41st among 41 athletes-Sturaro 26th, Strikers Pelle is 6th among 49 athletes. Immobile ranked 17th.

In general, 3-2-3-2 / 3-3-4 / 3-1-4-2 defense and 5-3-2 / 3-5-2 game understanding took more risks compared to the old years and especially the first It was observed that it displayed a view away from the strict defense understanding in the region. They wanted to steer the game by having more ball possession. We can only see the answer to the question of whether this game understanding is just coach effect or country football is changing in the next tournament.

Looking at the comments from all over the world, Italy changed the style and system of the game and it was evaluated that it applied new trends in football. For example;

- A very good team with tactical training that can play different systems,

- Different game systems are applied in different matches,

- Different game systems are used well in transition to offense and defense in the game,

- Game strategies were changed in the 2nd and 3rd regions,

- Players with better offense feature are preferred,

- The ball owner's desire to steer the game themselves,

- Instead of waiting for the opponent to make a mistake when they lose the ball, it is started to put pressure on the opponent,

- Especially in defense, players who have a good technical capacity, who have the ability to dominate the game, which can take control of the game, are not preferred,

- 35-40 m distances and distance between locations are well established,

- Instead of standing behind the ball, the opponent was directed to the press area to create pressure against the ball, and it was determined that the ball was wanted to have.

As the first zone area, the region starting from the penalty area to the middle line used a distance of approximately 40 meters. As the 2 nd region, the middle region of both half fields is used approximately 40 meters. 3As a region, the entire opponent half field was played at a distance of approximately 50-55 meters. The field view is shown below. 


\section{Figure 3: Distances between zones}

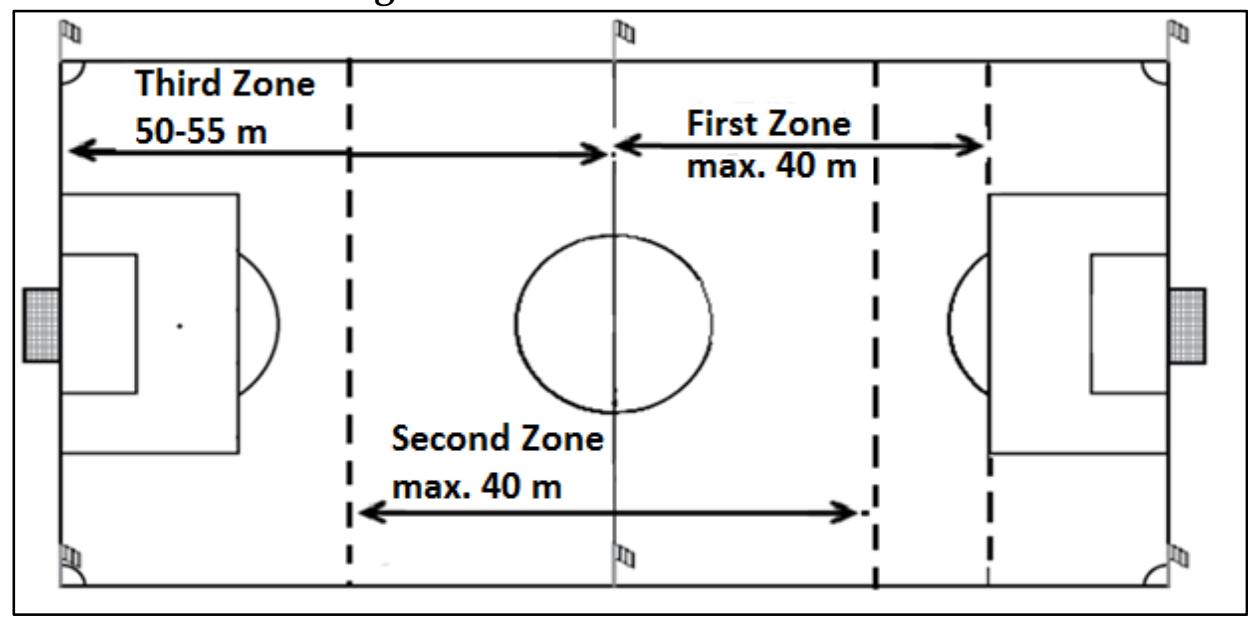

3.3 Team Lineups in The Offensive of the Italian Football Team in the Euro 2016 Championship

With the 3-defence setup, a group of players with good combat and technique, a game understanding that plays hard and plays from the ground in the defense has been exhibited. They formed the line of defense in the 2nd zone and played the gradual 5 midfield fiction by keeping the midfield crowded. Players with good offensive features were preferred. It was seen that they thought more goals with the double striker and they wanted to keep the game more on the field.

Figure 4: 3-2-3-2 game system and preferred features

(in


Figure 5: 3-2-3-2 system in offense

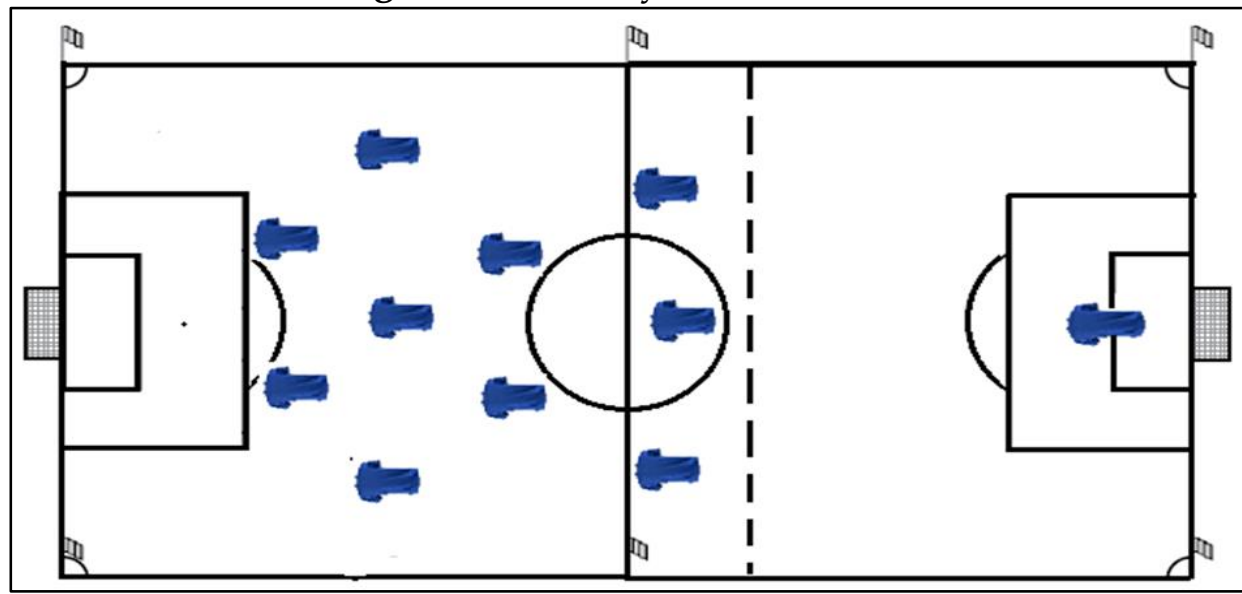

Figure 6: 3-3-4 system with staged midfield between the 2nd and 3rd regions in offense

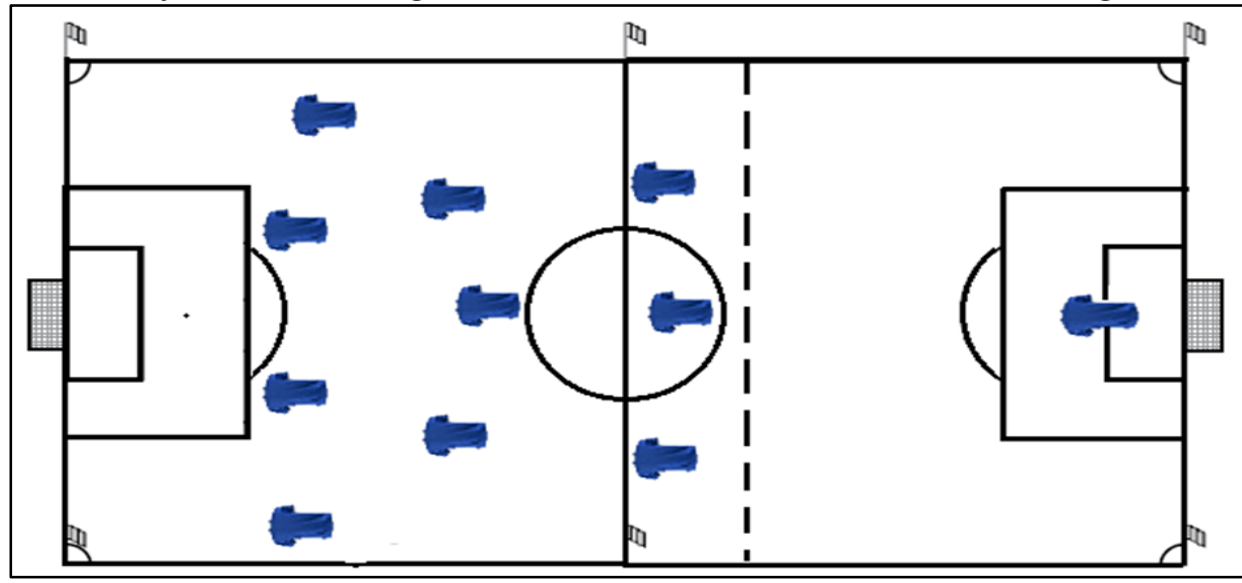

Figure 7: 3-1-4-2 system in offense

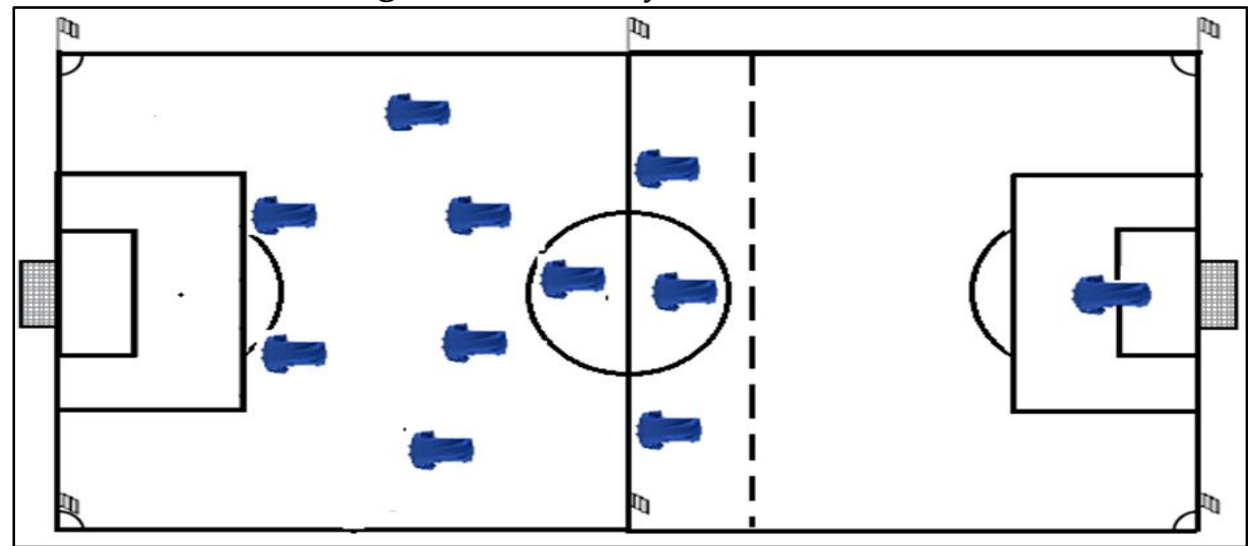

\subsection{Defense Lineups of the Italian Football Team in the Euro 2016 Championship}

It is determined that although Italian football tries to play offensive football, it does not compromise defense security. Defense was always started in the area where the ball was lost. Especially in the second region, defending was done in 3-5-2 game format at 40 meters in team length. This lineup in the field is shown below. 
Figure 8: 3-5-2 game system

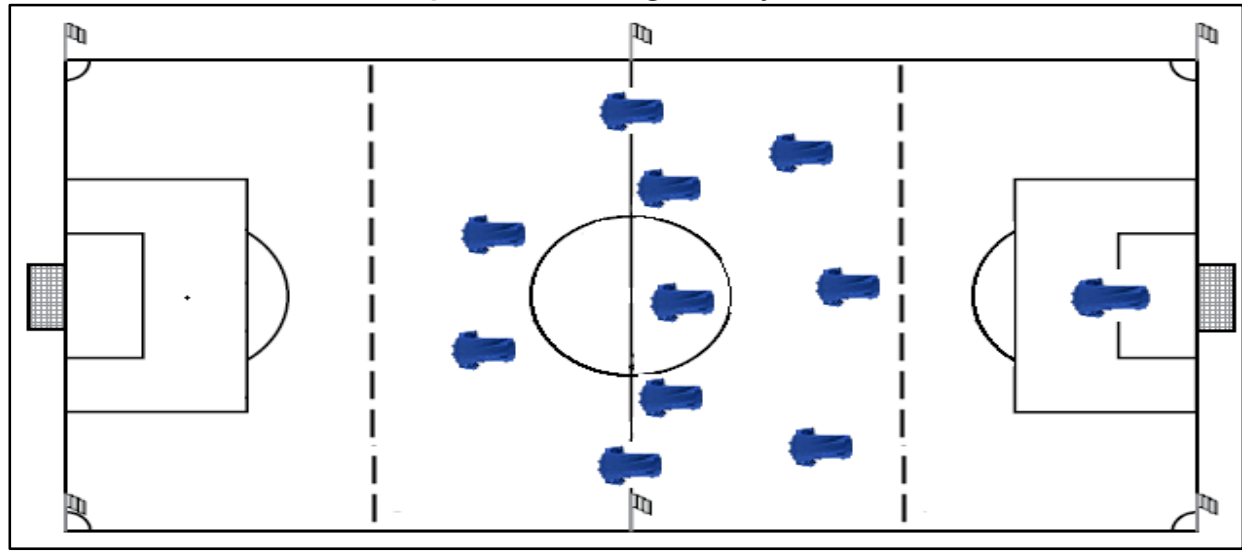

Figure 9: 5-3-2 game system

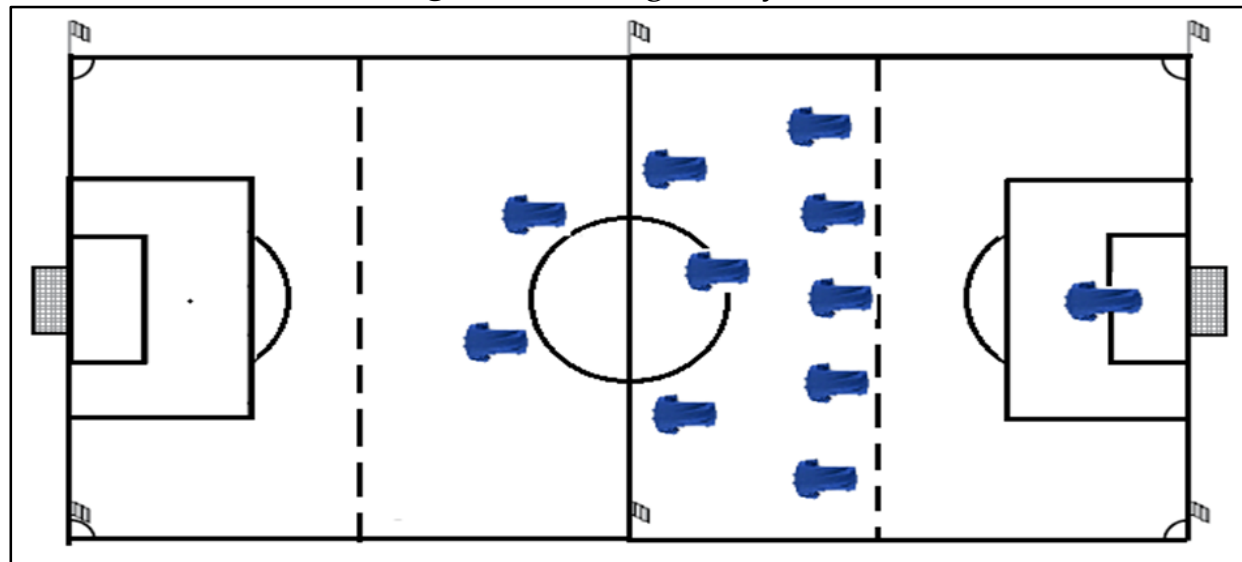

In the event that the ball cannot be taken in the first move, the two wings players in the 3-5-2 lineup come to the wings of the defender and passes to the line as the defense line 5-3-2. The biggest factor in the Italian football team's ability to make both offensive and defensive features in the best way is the selection of athletes. The following features come to the fore in these players:

- They made the start of the game well by using technical players

- Players with offensive and defensive features were preferred,

- Left-back player preferred with stopper feature,

- Right-back player preferred with stopper feature,

- Good stopper players who can use their feet well in air balls and when the ball is played from the ground are preferred,

- The player who preferred the transitions to attack and defense was preferred,

- The player who preferred the transitions to attack and defense was preferred,

- In the loss of the ball, they started the press and then directed the opponent to the press area and they did their part in the team. 
Figure 10: Pressure after ball loss

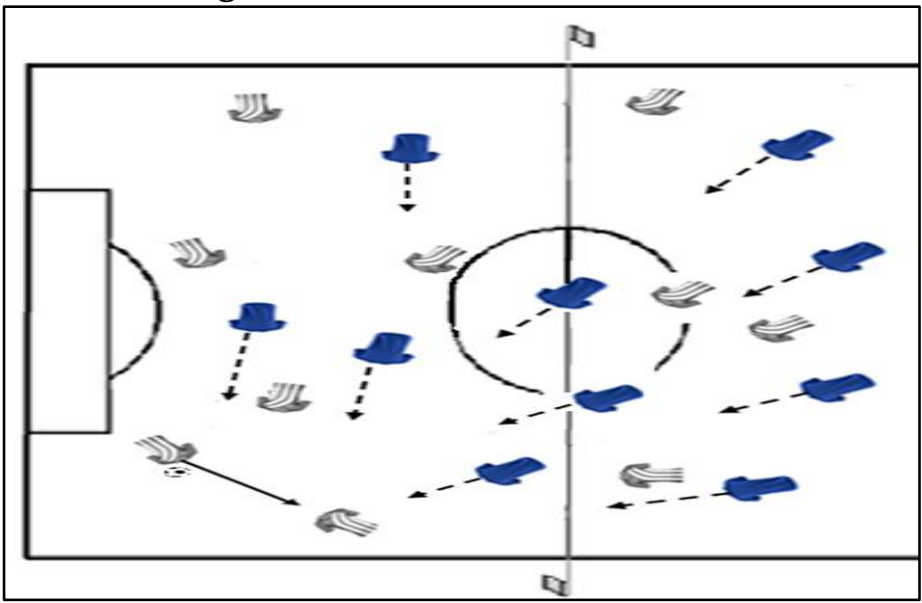

While the forward strikers press the players with weak ball technique in the teams losing the ball or playing backwards, the other players slip as a team and close the passes and the players who will get the pass.

Figure 11: Team taking position according to the direction of the ball

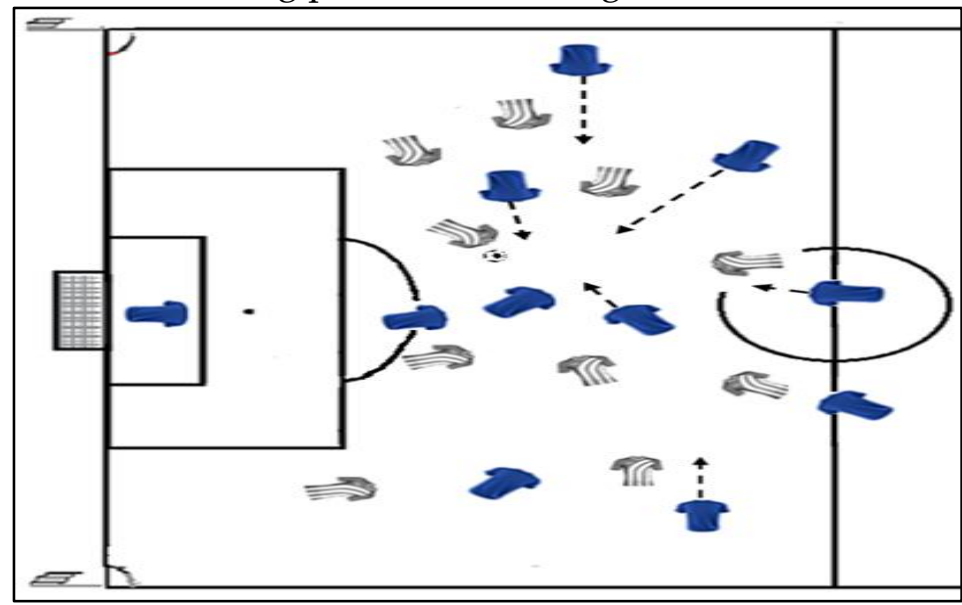

It is advantageous to lose the ball in the 3-2-3-2 line-up or to take a position according to the direction of the ball. The players closest to the ball make double or triple compression or move the ball to prevent people from taking the ball comfortably.

\section{Discussion}

Italy participated in the European Football Championship 8 times, played three finals and won this trophy in 1968. Before 2016, Italian football is a team that adopted the solid defense principle. It aims to achieve results based on free kicks and individual actions. With the 5-4-1 and 4-5-1 game system, the defense is not at risk and few players are attacked. Players with good defense power are preferred in the player choice. Italy ranked first in the groups at the 2016 European championship. In the qualifying round, the last champion eliminated Spain with 2-0. They were defeated to Germany in penalty 
shootout in the quarter-finals. As a result of the analyzes, differences were observed in the Italian football team over the years. It has been evaluated that Italy has changed its play style and system and applied new trends in football. It is a team chosen from players who can play different systems. Different game systems have been applied in different matches. Different game systems have been well implemented in the transition to attack and defense within the game. Players with better attacking feature are included in the team. Players with good technical capacity capable of dominating the game are preferred. The distance between the positions of 35-40 m has been well maintained and both defense and offensive have been made in these areas. It was determined that the ball was directed to the opponent press area to create pressure against the ball rather than waiting behind it and wanted to have the ball. In the Euro 2016 football championship, the Italian football team applied the 3-2-3-2 game system with the triple defense setup, a group of players who have good bilateral struggles and techniques, a game understanding that was playing hard and playing from the ground in defense was exhibited. They formed the line of defense in the 2 nd zone. The midfield was kept crowded and it was formed by players with good staged 5 midfield fiction and offensive aspects. It is determined that they think more goals with the double striker and want to keep the game more on the opponent field.

In general, 3-2-3-2 / 3-3-4 / 3-1-4-2 defense and 5-3-2 / 3-5-2 game understanding took more risks compared to the old years and especially the first it was observed that they display an image far from the strict defense understanding in the region. Players with better offensive and defensive features were preferred for these systems. Technical stopper players are preferred when the ball is played from the ground. Players who prefer the transitions to attack and defense are preferred. An image that demonstrates tactical field shrinkage, press together, directing the opponent to possess the ball (without waiting for the opponent's mistakes only), transition to different systems in the game has been exhibited. It is determined that they are a very good team trained tactically in terms of taking the ball very well according to the direction of the ball.

\section{Conflict of Interest}

No potential conflict of interest was reported by the authors.

\section{About the Author}

Doctor Lecturer Kemal Kurak, Çanakkale Onsekiz Mart University, Faculty of Sport Sciences, Department of Recreation, Çanakkale, Turkey. Research interests: sport science, movement and training, coaching, football.

Research Assistant Hakan Büyükçelebi, İnönü University, Faculty of Sport Sciences, Department of Coaching Education, Malatya, Turkey. Research interests: sport science and technology, movement and training, analysis in sport, football analysis.

Professor Doctor Mahmut Açak, Çanakkale Onsekiz Mart University, Faculty of Sport Sciences, Department of Coaching Education, Çanakkale, Turkey. Research interests: sport science, movement and training, sports injuries, sports rehabilitation, coaching, football. 


\section{References}

Carling, C., Williams, A. M., \& Reilly, T. 2005. Handbook of Soccer Match Analysis: A Systematic Approach to Improving Performance. London \& New York: Taylor \& Francis Group.

Clemente, F., Couceiro, M., Martins, F. \& Mendes, R. 2012. Team's performance on FIFA U17 World Cup 2011: Study based on notational analysis. Journal of Physical Education and Sport. 12(1): 13-17.

Helgerud, J., Engen, L. C., Wisløff, U. \& Hoff, J. 2001. Aerobic Endurance Training Improves Soccer Performance. Medicine \& Science in Sports and Exercise. 33(11): 1925-1931.

Hughes, M. D. \& Bartlett, R. M. 2002. The use of performance indicators in performance analysis. Journal of Sports Sciences. 20(10): 739-754.

Lago-Peñas, Carlos, Joaquín Lago-Ballesteros, Alexandre Dellal, and Maite Gómez. 2010. Game-Related Statistics That Discriminated Winning, Drawing and Losing Teams from the Spanish Soccer League. Journal of Sports Science and Medicine, 9(2):288293.

Luhtanen, P. 1990. Video Analysis of Technique and Tactics, International Conference "Sports Medicine Applied to Football". Roma 5-7 Mari.

Mackenzie, Rob, and Chris Cushion. 2013. "Performance Analysis in Professional Soccer: Player and Coach Perspectives." IX Performance Analysis of Sport Congress.

Manna, I., Khanna, G. L., \& Dhara, P. C. 2011. Effect of Training on Morphological, Physiological and Biochemical Variables of U-19 Soccer Players. Baltic Journal of Health and Physical Activity, 3(4): 237-27.

Sajad, N., Rahnama, N. Analysis of goals in 2006 FIFA World Cup. 2007. VIth World Congress on Science and Football, Book of Abstracts. January 16-20, Antalya, Turkey.

Shafizadeh, M., Taylor, M., \& Lago Peñas, C. 2013. Performance consistency of international soccer teams in Euro 2012: a time series analysis. Journal of Human Kinetics, 38: 213-225. 
Kemal Kurak, Hakan Büyükçelebi, Mahmut Açak

ANALYSIS OF THE ITALIAN FOOTBALL IN THE 2016 EUROPEAN FOOTBALL CHAMPIONSHIP

Creative Commons licensing terms

Authors will retain the copyright of their published articles agreeing that a Creative Commons Attribution 4.0 International License (CC BY 4.0) terms will be applied to their work. Under the terms of this license, no permission is required from the author(s) or publisher for members of the community to copy, distribute, transmit or adapt the article content, providing a proper, prominent and unambiguous attribution to the authors in a manner that makes clear that the materials are being reused under permission of a Creative Commons License. Views, opinions and conclusions expressed in this research article are views, opinions and conclusions of the author(s). Open Access Publishing Group and European Journal of Physical Education and Sport Science shall not be responsible or answerable for any loss, damage or liability caused in relation to/arising out of conflict of interests, copyright violations and inappropriate or inaccurate use of any kind content related or integrated on the research work. All the published works are meeting the Open Access Publishing requirements and can be freely accessed, shared, modified, distributed and used in educational, commercial and non-commercial purposes under a Creative Commons attribution 4.0 International License (CC BY 4.0). 